\title{
Innóvate y la Universidad Ricardo Palma Proyecto ganador - FINCyT
}

$\mathrm{E}$ n la última convocatoria realizada por el Fondo para la Innovación, Ciencia y Tecnología (FINCyT) del Ministerio de la Producción, el proyecto "Sistema electromecánico de simulación sísmica basado en registros sísmicos del Perú para evaluar el comportamiento sismo-resistente de sistemas constructivos”, presentado por la Arq. María Teresa Méndez Landa, Coordinadora General del Proyecto; el Sr. Juan Gonzales Lévano, Tesista de Ingeniería Electrónica; y los investigadores, el Ing. Pedro Huamaní Navarrete y el Ing. Gustavo Roselló Moreno, de la Facultad de Ingeniería de la Universidad Ricardo Palma, resultó ganador.

Este proyecto busca desarrollar un sistema electromecánico bidireccional de simulación sísmica para pruebas dinámicas de evaluación del comportamiento sismo-resistente útil en diversos sistemas constructivos con data basada en registros sísmicos del Perú. Será financiado con un presupuesto total de S/ 779,585.00, gracias al soporte financiero otorgado por el FINCyT-Innóvate y la Universidad Ricardo Palma. En lo referente al FINCyT, se cuenta con una aportación financiera de S/ 314,525.00, con el código del proyecto PIAP-3-P-553-14 y el número de convenio 166-PNICPPIAP-2015. Debe realizarse en un plazo de dieciocho meses a

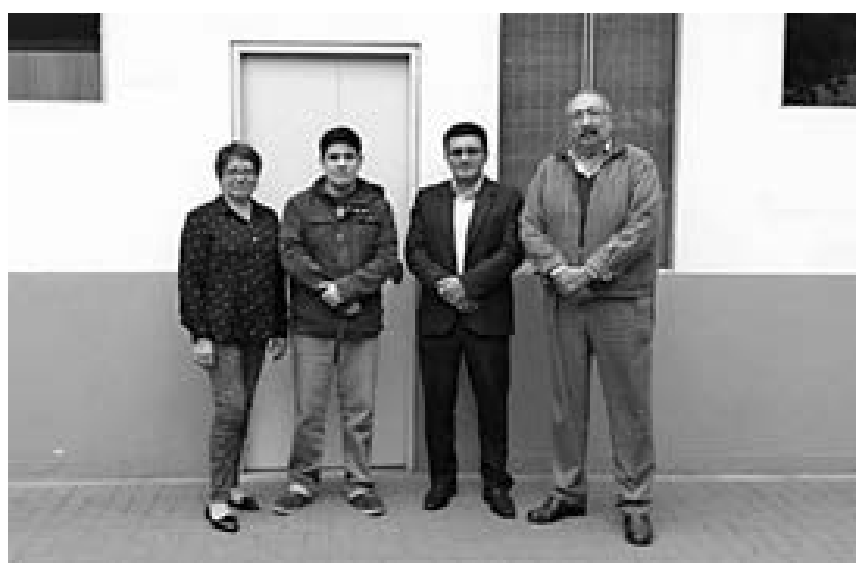

Figura 1: Equipo técnico del proyecto. De izquierda a derecha: Teresa Méndez, Coordinadora General del Proyecto, Juan Gonzales, Tesista de Ingeniería Electrónica, y los investigadores Pedro Huamaní y Gustavo Roselló Moreno. partir de la firma del contrato, realizada en agosto del 2015.

Este proyecto cuenta con la asesoría de especialistas (además de los anteriores) como el Ing. Miguel Ángel Sánchez Bravo, asesor en la especialidad de control, y el Dr. Ing. Carlos Zavala Toledo, asesor de Ingeniería Civil. Para realizar las coordinaciones y control presupuestal del proyecto, el Ing. Antonio Bravo Quiroz participa como coordinador administrativo y el Sr. Luis Chiyutupa como tesista en Ing. Civil. 